\title{
The contribution of nursing preceptors to the future nursing workforce
}

\author{
L Hugo, RN, RM, PhD; Y Botma, RN, RM, PhD \\ School of Nursing, Faculty of Health Sciences, University of the Free State, Bloemfontein, South Africa
}

Corresponding author: L Hugo (hugol1@ufs.ac.za)

Background. Apart from a global need for more nurse practitioners, there is also a need for nurse practitioners who are competent and confident to address the needs of their communities. Furthermore, the future nursing and midwifery workforce needs to have effective interprofessional collaboration skills and a person-centred approach. A clinical model, accepted by the National Department of Health in 2011, places preceptors at the centre of clinical education to assist in the improvement thereof and to develop much-needed attributes in nursing students. No research has been conducted to explore the way in which preceptors see their contribution to developing the future nursing workforce.

Objective. To explore preceptors' views of their contribution to the development of the future nursing workforce.

Method. A qualitative, visual, narrative inquiry design was used. Following a 3-day preceptor-training workshop, 38 preceptors from two nursing education institutions collectively participated in creating images of their views on their contribution to developing the future nursing workforce. The first 6 steps in the visual analysis were used to analyse the images.

Results. Six categories originated from the images, i.e. skill set, stakeholders, diverse students, transformative learning, relationships and practice.

Conclusion. Preceptors are more than handmaidens of the educational system. They may contribute significantly to the development of the nurse and midwife workforce, as they promote competence, people-centredness and interprofessional collaboration, which are strategies proposed by the World Health Organization for reaching universal health coverage.

Afr J Health Professions Educ 2020;12(3):109-113. https://doi.org/10.7196/AJHPE.2020.v12i3.1372

Nurses have much more to offer than merely being the handmaidens of doctors and performing psychomotor skills, especially in countries that aim for universal health coverage (UHC) and those with healthcare disparities. ${ }^{[1]}$ Threats to UHC include unfit-for-purpose human resources, insufficient numbers and inequitable distribution of healthcare workers. ${ }^{[2]}$ As an example, we refer to the study by Freer, ${ }^{[3]}$ who reported that in 2017, $12 \%$ of doctors worked in rural areas of South Africa (SA), where $46 \%$ of the population were living. While sub-Saharan Africa carries $25 \%$ of the world's disease burden, only $3 \%$ of the global health workforce resides there. ${ }^{[4]}$ Therefore, the needs-based projection by Scheffler et al..$^{[5]}$ shows that lowand middle-income countries will have a shortage of 6 million healthcare professionals by 2030. Asamani et al. ${ }^{[2]}$ therefore warn that there is little hope of meeting the human resources need because governments are unable to pay the wage bill.

The education of healthcare professionals should focus on meeting the needs of the health system and communities ${ }^{[6]}$ and not only on increasing the number of nurses being trained. The importance of this focus should be on quality rather than quantity of nurses, as noted by Drennan and Ross. ${ }^{[7]}$ Although more healthcare professionals - especially nurses - are required, more relevant training through intra- and interprofessional collaboration, education and continuous professional development is needed to maximise the capacities and potentials of nurses and midwives. ${ }^{\left[{ }^{[8]}\right.}$ Relevant training relates to curriculum relevance, a person-centred approach and continuous skills development. ${ }^{[9,10]}$ Hence, innovations in health professions education are urgently needed to develop an adequate and skilled health workforce. ${ }^{[1]}$
In addition to other educational approaches, Rwanda emphasises simulationbased and clinical education, thereby intending to promote critical thinking and clinical reasoning skills of nursing students. ${ }^{[4]}$ Preceptors are ideal to promote critical thinking and clinical reasoning in students. In 2011, the National Department of Health accepted a clinical teaching model in which nursing education institutions (NEIs) employ preceptors to accompany nursing students during their clinical placements. ${ }^{[12]}$ The named strategies aim to improve the quality of nursing education, as well as that of the nursing workforce. However, the authors could not find literature on preceptors' perceptions of their contribution to the development of the future nursing workforce. In this article, we report on a study that explored preceptors' views of their contribution to the development of the nursing workforce.

\section{Methods}

The researchers used a qualitative, visual, narrative inquiry design ${ }^{[13]}$ to explore participating preceptors' views on their contribution to developing the future nursing workforce. Through an interpretive stance, the researchers gained insight into the reality as perceived by preceptors within their specific context.

\section{Population}

The first author presented the preceptor-training programme at two NEIs. Census sampling allowed all preceptors at both NEIs to participate in the study. Thirty-eight preceptors attended the training programme, and the images that the preceptors created collectively in groups comprised one deliverable of the programme. 


\section{Data collection}

At the end of the 3-day preceptor-training programme, participants created an image on the collective views of their contribution in developing the future nursing workforce of 2030. Among the two NEIs, 8 images were developed, but 3 were not submitted by participants, leaving the researchers with 5 images for analysis.

\section{Data analysis}

Following Mey and Dietrich, ${ }^{[14]}$ the first 6 steps in the visual analysis in combination with an adapted image-analysis worksheet created by the US National Library of Medicine ${ }^{[15]}$ were used to analyse the images. The worksheet guided the researchers in describing the images by focusing on details regarding people, actions, objectives, symbols and questions, which captured the first 3 steps of Mey and Dietrich, ${ }^{[14]}$ i.e. contextualisation, description and segmentation. Steps 4 and 5 of Mey and Dietrich ${ }^{[14]}$ comprise memo writing, coding and interpretation. These steps correspond with the coding of the worksheet as missing information and the main messages portrayed by the images.

\section{Ethical approval}

The Health Sciences Research Ethics Committee and research sites approved the study (ref. no. ECUFS 134/2013B). All the preceptor-training attendees gave written informed consent that the first author may use all deliverables for research.

\section{Results}

In line with the first 3 steps of Mey and Dietrich, ${ }^{[14]}$ a brief description of each image is provided, followed by the coding and interpretation.

Fig. 1 reflects the upper body of a woman with two red bows in her hair, a green band around her neck and an inverted red triangle in the lower third of her thorax. She has prominent shoulders on which is written, 'Carry all the burden' and 'Willing horse'. Her heart is a passion for teaching, with an electrocardiogram (ECG) rhythm strip. Both arms are stakeholders. Her senses characterise the preceptor as a good listener and observer; her mouth tells no lies and is decisive. Other characteristics flow over her right shoulder. The triangles in the corners state copy time 10, 100 and 1000 . Her legs are a vehicle for clinical teaching and transformation.

The stick figure in the bottom left-hand corner of Fig. 2 wears a hat with the SA flag, and holds 3 torches shining towards student education, practice and management. The lines between the stick figure and education, practice and management are linear and star studded. A sketch of a tie appears next to management. The students - depicted as multicoloured dots with various expressions - are in the middle of a practice circle. There are also question marks in the circle. A spiral forms the link between the stick figure and the students. Education is portrayed in an elliptical form with a graduation cap, and crosses practice to meet the students in the middle of the practice circle.

Fig. 3 is a tree with branches and leaves in the upper third of the page. The branches represent thoughts, while the leaves depict characteristics of the preceptor. Stakeholders are captured in the trunk. A green ribbon is wrapped around the trunk and is fastened with a red heart, with the words 'Art of preceptorship'. 'Building the future' is written in the soil. Beneath the soil are the roots, depicting ethics, standards, foundational knowledge, communication pathway, clinical and theoretical expertise,

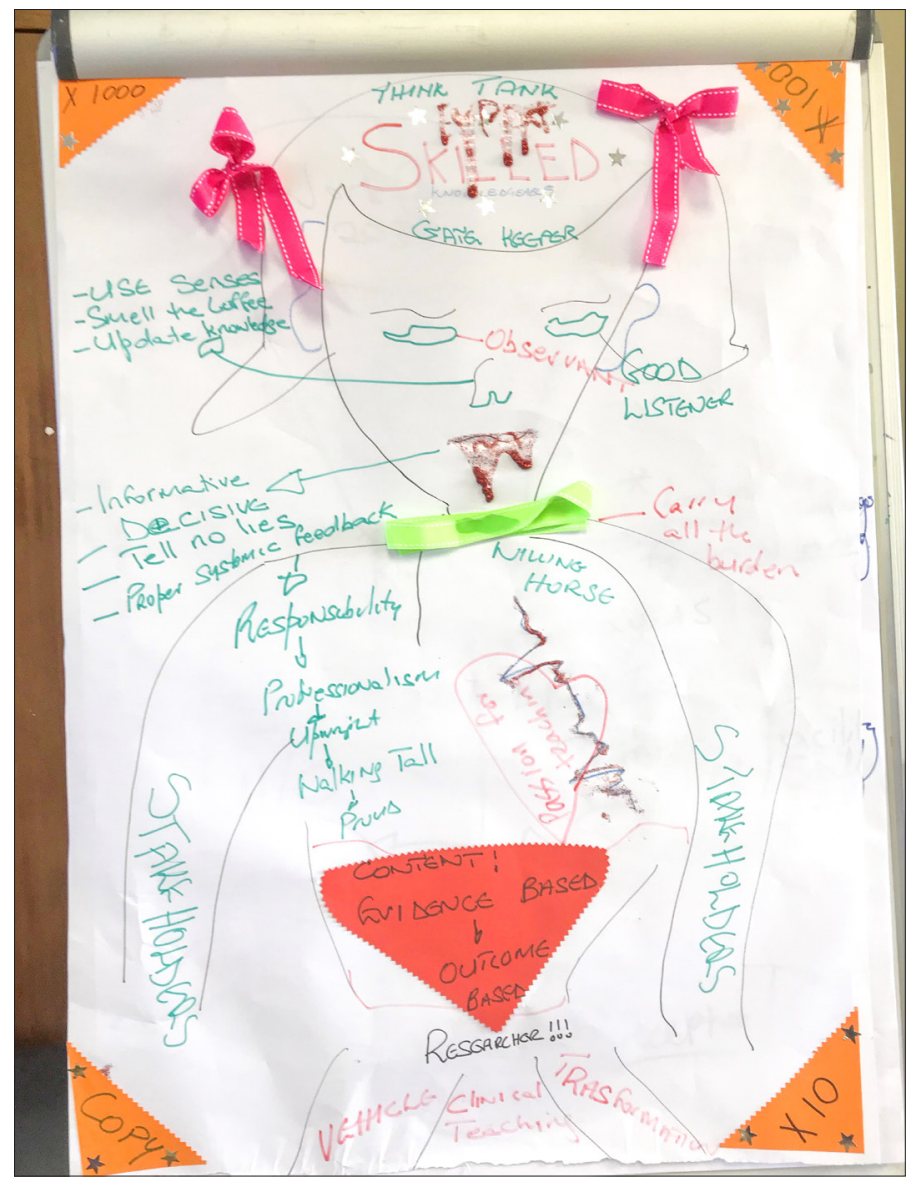

Fig. 1. The upper body of a woman.

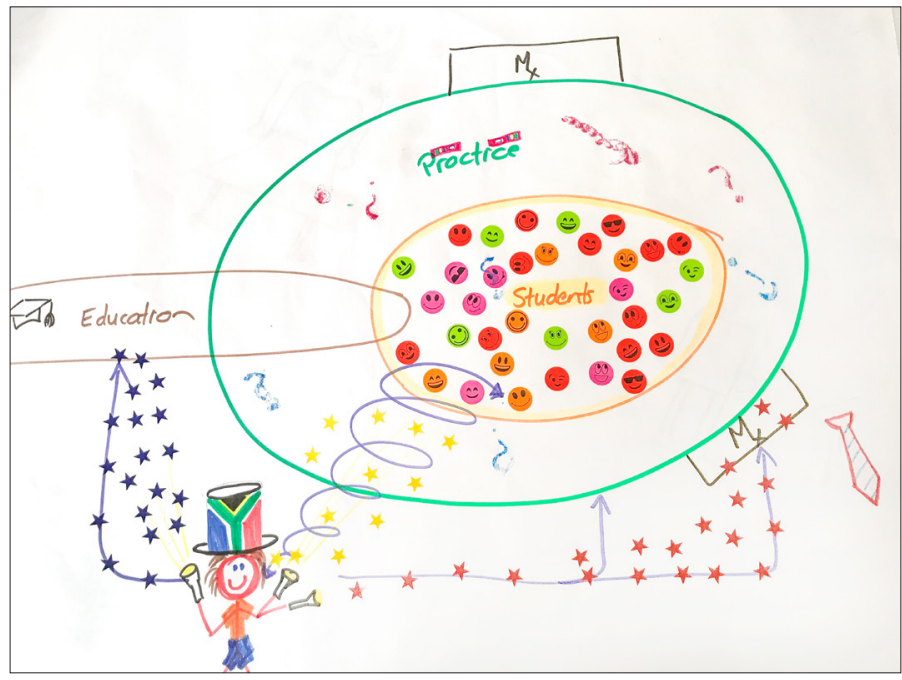

Fig. 2. Shining a light.

recruitment process, role models and mentors. The preceptor and facilitation techniques are shown as raindrops.

Paper figures with different facial expressions and coloured dots fill the bottom half of Fig. 4. Stars on the images may indicate the level of study, as they vary from 1 to 4 . Centred in the top half is a paper image similar to the one in the bottom half. This figure holds on to two chains overarching 


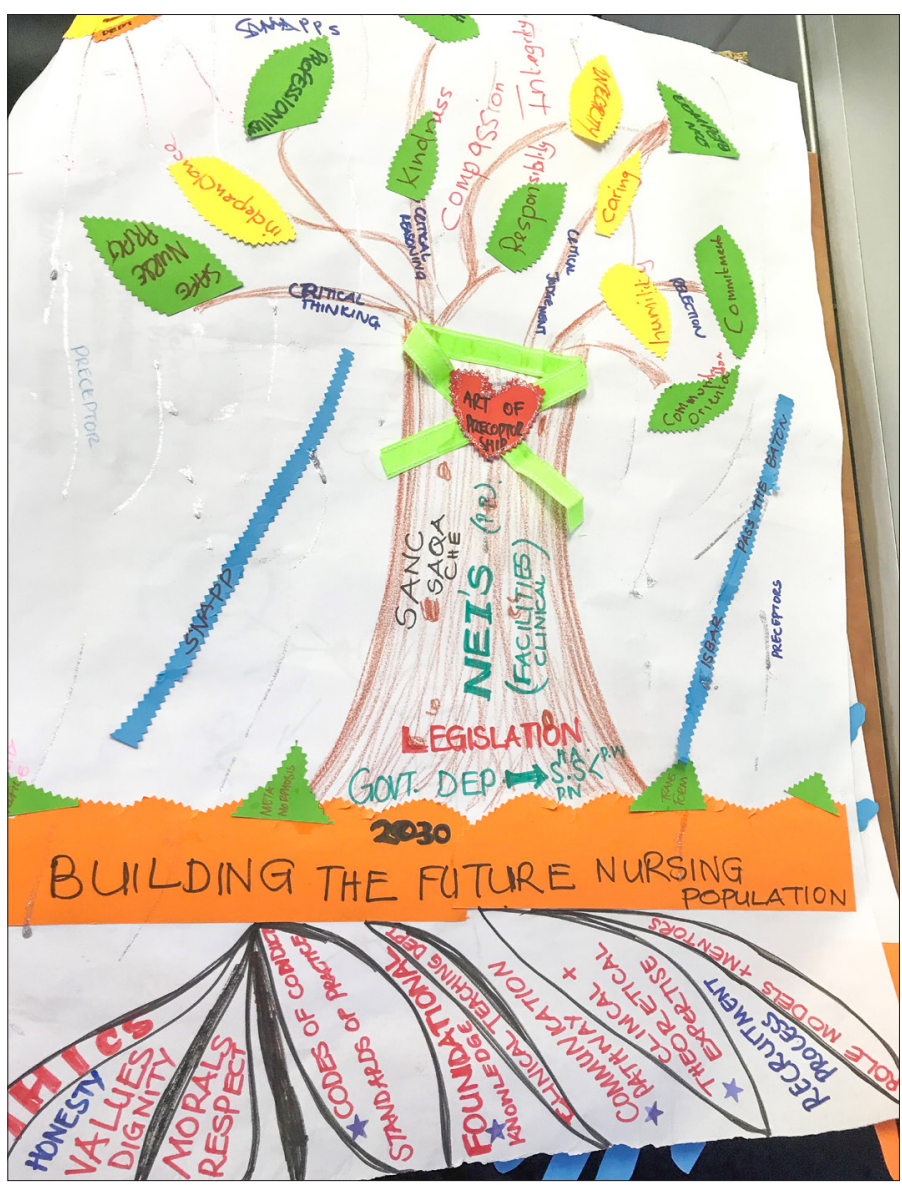

Fig. 3. The tree.

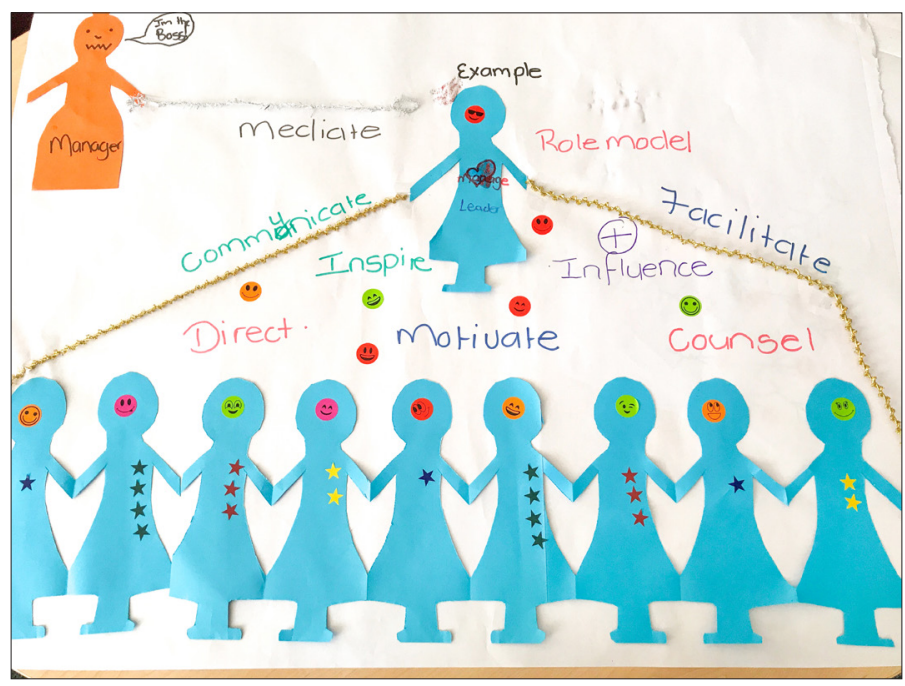

Fig. 4. Holding hands.

the images in the bottom half of the representation. The surrounding words portray tasks such as communication and facilitation. In the top left-hand corner is a different image (manager) who holds a whip. Above the manager are the words 'I am the boss'.

In Fig. 5 there are 2 females - on opposite sides of the page. The lefthand one is more prominent and colourful than the one on the right, which

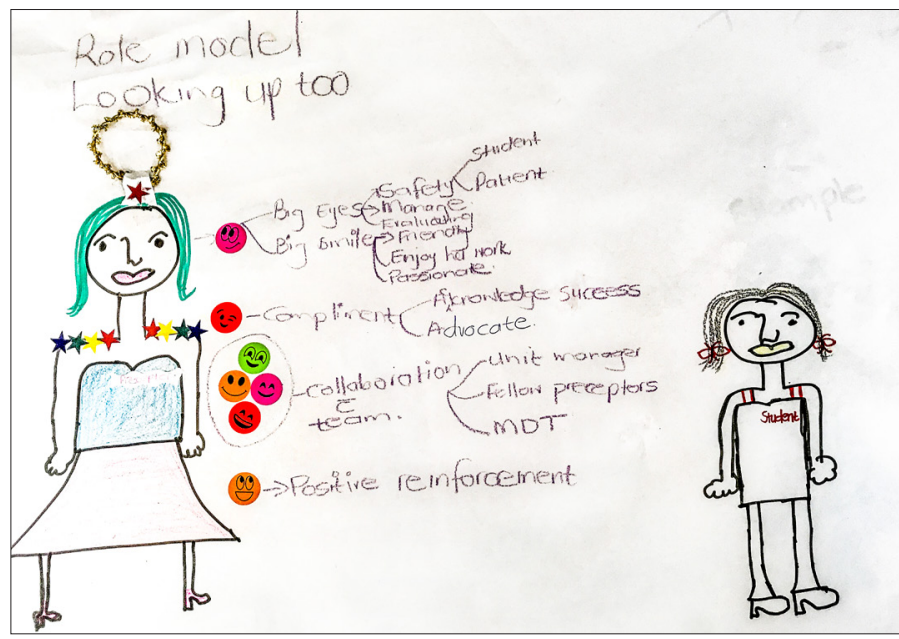

Fig. 5. The preceptor and the student.

represents a student. The preceptor, on the left, has a halo with the words, 'Role model' and 'Looking up to.' The words surrounding the preceptor indicate her tasks, such as 'manage', 'evaluate' and 'collaborate' with 'unit managers', 'fellow preceptors' and 'multidisciplinary team'. Preceptor characteristics, such as 'friendliness', 'compassion', 'acknowledging success' and 'advocate' are associated with the large mouth. The preceptor also gives positive reinforcement. There is no link between the preceptor and the student, but rather a great distance.

The researchers noticed information missing on the images, which they had expected to find in the context of preceptorship. Only Fig. 2 portrays the clinical context where preceptors primarily work. Students with whom preceptors engage are absent from Figs 1 and 3. Figs 4 and 5 lack stakeholders involved in students' clinical learning.

The coded messages were then grouped into 5 categories. Table 1 shows the categories, i.e. skill set, stakeholders, diverse students, transformative learning, relationships and practice. The numbers indicate Figs $1-5$, which portray the information.

The categories mentioned are discussed in the following section, with theoretical links to indicate rationale and guide NEIs in terms of important elements for inclusion in future training programmes.

\section{Discussion}

Preceptors are the lynchpin between the educational system and health system, as they liaise with stakeholders involved in students' clinical learning (Figs 1 and 2) ${ }^{[16,17]}$ Stakeholders include but are not limited to placement co-ordinators, educators, programme directors, unit managers, nurse practitioners, students and patients. ${ }^{[18]}$ Figs $1,3,4$ and 5 illustrate the importance of a specific skill set that preceptors should have. For example, negotiation skills are pivotal for collaboration with the stakeholders to arrange learning opportunities for students. ${ }^{[19,20]}$ They thereby contribute to a positive clinical learning environment where students can integrate theory into practice.

Four of the 5 images highlight the skill set of preceptors, which enables them to facilitate the development of students' critical thinking, clinical reasoning and problem-solving skills - contributing to students becoming competent, autonomous practitioners..$^{[20,21]}$ Crisp and Watkins ${ }^{[1]}$ concur that nurses should move away from being mere handmaidens who practise 


\begin{tabular}{|c|c|}
\hline Category & Main message per image \\
\hline Skill set & $\begin{array}{l}\text { Preceptors need a specific skill set, e.g. being skilful, knowledgeable, a good listener, a communicator, observant, } \\
\text { compassionate, a collaborator with stakeholders, a facilitator, a role model, a mediator and an assessor (Figs 1, 3, } 4 \text { and 5) } \\
\text { Facilitation techniques are specific to the development of thinking operations (Fig. 3) }\end{array}$ \\
\hline Stakeholders & $\begin{array}{l}\text { The preceptor stands central to the stakeholders (Fig. 1) } \\
\text { Preceptor as a link between education, student, practice and practice management (Fig. 2) } \\
\text { Preceptors comprise the essential element (rain) that allows the fundamental requirements, through the governance of } \\
\text { stakeholders, to be absorbed and to feed the branches and leaves to portray a healthy nursing workforce (Fig. 3) }\end{array}$ \\
\hline Diverse students & The diverse student population in practice (Figs 2 and 4 ) \\
\hline Clinical learning & $\begin{array}{l}\text { The preceptor is the vehicle for clinical learning (Fig. 1) } \\
\text { The preceptor recognises that students are at different levels and adapts facilitation accordingly, as illustrated by the spiral } \\
\text { between facilitator and students in practice (Fig. 2) }\end{array}$ \\
\hline Relationships & $\begin{array}{l}\text { An autocratic relationship exists between the manager and the preceptor, while the preceptor embraces the students (Fig. 2) } \\
\text { There is a power distance between the preceptor and the student, as shown in the space between them and the difference } \\
\text { in size (Fig. 5) }\end{array}$ \\
\hline Practice & $\begin{array}{l}\text { The size of practice may indicate the importance of student development towards competence, and also the context of their } \\
\text { place of work (Fig. 2) }\end{array}$ \\
\hline
\end{tabular}

psychomotor skills, and instead refocus on integration of knowledge, psychomotor skills and people-centred behaviour to achieve UHC. Fig. 3 shows specific techniques, such as SNAPPS (summarising, narrowing, analysing, probing, planning and selecting), ISBAR (introduction, situation, background, assessment and recommendation) and I PASS the BATON (introduction, patient, assessment, situation, safety concerns, background, actions, timing, ownership and next) as ways to facilitate students' learning. ${ }^{[17,20]}$ Effective facilitation develops self-directedness in students, resulting in lifelong learners. Lifelong learning is a critical characteristic for practitioners to be able to cope with emerging technology and scientific healthcare knowledge. ${ }^{[22]}$

Student learning occurs primarily in practice, which is often a challenging and unpredictable environment, as illustrated by means of question marks (Fig. 2). It is noticeable that only 1 of the 5 images includes the clinical context. Challenges refer to a poor human-resourced environment, together with a lack of consumables, such as medicinal drugs, and inadequate or malfunctioning equipment, which may have a negative influence on developing a competent workforce for 2030. ${ }^{[11]}$ The support preceptors provide to students is, therefore, essential to promote students' clinical learning. ${ }^{[17]}$

Students often experience clinical practice as stressful and unfriendly. ${ }^{[2,23]}$ Preceptors should therefore provide emotional support in practice. ${ }^{[17]}$ Building interpersonal relationships with students is essential to provide emotional support, depicted in Fig. 4 as the preceptor protecting students. Students who experience support from preceptors may be able to manage challenging situations in practice. ${ }^{[17]}$

Additionally, interpersonal relationships with stakeholders contribute to a positive clinical learning environment. ${ }^{[18]}$ Stakeholders in the clinical environment include other healthcare professionals, as interprofessional collaboration during clinical learning is essential to abolish the biomedical model and promote a biopsychosocial approach to healthcare. ${ }^{[24]}$ Fig. 5 portrays collaboration with the teams, emphasising the unit manager, fellow preceptors and the multidisciplinary team.

However, according to preceptors, managers are perceived as autocratic (Fig. 4), endangering the establishment of personal relationships with others.
Other stakeholders are absent (Figs 4 and 5). Preceptors' relationships with stakeholders are essential for students to flourish in the clinical learning environment.

Interpersonal relationships are embedded in person-centredness, embracing the diversity of students and healthcare consumers. Figs 2 and 4 show the diversity of students by way of different colour stickers, varying facial expressions, and the number of stars illustrating the educational level of students. Person-centred preceptors consider students' personalities, learning styles, motivation, cultural backgrounds, different educational levels and circumstances during the facilitation of learning. ${ }^{[25]}$ Subsequently, students will be motivated to transfer their learning and improve their nursing care practices. Traditionally, preceptorship focused on demonstrating psychomotor skills and assessments. ${ }^{[17]}$ This left limited space for relationship building with students, and might have been the reason for the power distance (Fig. 5). Also noticeable is that students are absent from Figs 1 and 3.

\section{Conclusions}

Preceptors created images on how they perceived their contribution to the future nursing workforce of 2030. Five images were analysed according to Mey and Dietrich's ${ }^{[14]} 6$ steps. Preceptors need a specific skill set to develop competence in students. From the images, participating preceptors became aware that they should move away from psychomotor skills training and assessment and focus on facilitating the integration of knowledge, skills and behaviour, thereby developing a competent nursing workforce. Images portrayed that stakeholders in the educational and health system should work together to create a positive clinical learning environment for students to transfer their learning into practice and become competent. Preceptors view their liaising role with the educational and health system as essential for stakeholder collaboration. Interprofessional collaboration could be role-modelled by preceptors through the facilitation of clinical learning across healthcare professions. Several images portrayed the importance of relationships, taking into consideration the diversity of students and personcentredness in practice. The authors' interpretation of the preceptors' views regarding their contribution to the workforce for UHC is to develop 
students' clinical competence, and cultivate stakeholder collaboration, person-centredness and interprofessional collaboration.

A limitation is that the interpretation is based on the authors' perspective and theoretical explanations for insight into refining the training programme. Readers might view images from a different perspective and therefore generalisations cannot be made. Although a small study, the findings may be transferable to similar preceptor programmes. A larger study is needed to verify the findings of this study.

Preceptors are more than mere handmaidens of the educational system. They may contribute significantly to the development of the nursing and midwifery workforce, as they emphasise competence, people-centredness and interprofessional collaboration - strategies proposed by the World Health Organization for reaching UHC.

\section{Recommendations}

Future studies could investigate the effect of preceptors on workforce development. Preceptors should be trained to contribute to the development of a competent nursing workforce.

\section{Declaration. None.}

Acknowledgements. We acknowledge the participating preceptors at the two nursing education institutions.

Author contributions. The authors contributed equally to the article.

Funding. The research was funded by the PLUME FUNDISA/NRF grant (2015/001).

Conflicts of interest. None.

1. Crisp N, Watkins M. The triple impact of nursing. Int J Nurs Stud 2018;78:A3-A4. https://doi.org/10.1016/ ijnurstu.2017.05.001

2. Asamani JA, Akogun OB, Nyoni J, Ahmat A, Nabyonga-Orem J, Tumusiime P. Towards a regional strategy fo resolving the human resources for health challenges in Africa. BMJ Glob Health 2019;4(Suppl 9):e001533. https:/ doi.org/10.1136/bmjgh-2019-001533

3. Freer J. Sustainable development goals and the human resources crisis. Int Health 2017;9(1):1-2. https://doi. org/10.1093/inthealth/ihw042
4. Uwizeye G, Mukamana D, Relf M, et al. Building nursing and midwifery capacity through Rwanda's human resources for health program. J Trans Nurs 2018;29(2):192-201. https://doi.org/10.1177/1043659617705436 5. Scheffler RM, Campbell J, Cometto G, et al. Forecasting imbalances in the global health labour market and devising policy responses. Hum Resource Health 2018;16(1):1-11. https://doi.org/10.1186/s12960-017-0264-6 6. Da Silva FM, Gutierrez JFG. Transforming health professions education to advance toward universal health Int Am J Med Health 2018;1:1-3. https://doi.org/10.31005/iajmh.vli1.45

7. Drennan VM, Ross F. Global nurse shortages: The facts, the impact and action for change. Br Med Bull 2019;130(1):25-37. https://doi.org/10.1093/bmb/ldz014

8. Nkowane A, Ferguson S. The World Health Organization launches the 2016 - 2020 global strategic directions for strengthening nursing and midwifery. Nurs Econ 2016;34(4):206-208. https://doi.org/10.1213/ ane.0000000000003438

9. Mamede MV. Nursing and midwifery workforce and the new sustainable development goals (2016 - 2030). Rev Rene 2018;18(6):710-711. https://doi.org/10.15253/2175-6783.2017000600001

10. Van Vliet K, Roodbol P, Chorus A, Ossebaard H. Education for future health care: A radical shift in perception, learning and action. Int J Healthcare 2017;4(1):1-4. https://doi.org/10.5430/ijh.v4n1p1

11. Agyepong I, Sewankambo N, Binagwaho A, et al. The path to longer and healthier lives for all Africans by 2030 The Lancet Commission on the future of health in sub-Saharan Africa. Lancet 2017;390(10114):2803-2859. https://doi.org/10.1016/s0140-6736(17)31509-x

12. Nursing Education Stakeholders. A Proposed Model for Clinical Nursing Education and Training in South Africa. Pretoria: Forum of University Nursing Deans in South Africa (FUNDISA), 2012:49-58.

13. Given L, ed. The Sage Encyclopedia of Qualitative Research Methods, vol. 1-2, 2008. https://books.google.com/ books?id=y_0nAQAAMAAJ\&pgis=1 (accessed 23 March 2020).

14. Mey G, Dietrich M. From text to image: Shaping a visual grounded theory methodology. Historic Soc Res 2018:42(4):280-300. https://doi.org/10.17169/fqs-17.2.2535

15. United States National Library of Medicine. Image analysis worksheet. http://www.nlm.nih.gov/picturesofnursing (accessed 1 April 2020).

16. Botma Y, Hurter S, Kotze R. Responsibilities of nursing schools with regard to peer mentoring. Nurs Educ Today 2012:33(8):808-813. https://doi.org/10.1016/j.nedt.2012.02.021

17. Hugo L. Development and implementation of a training programme for preceptors: A realist evaluation. $\mathrm{PhD}$ Hugo L. Development and implementation of a training programme for preceptors: A realist evaluation. PhD
thesis. Bloemfontein: University of the Free State, 2018. https://scholar.ufs.ac.za/handle/11660/9879 (accessed thesis. Bloemfontein: University of the Free State, 2018. https://scholar.ufs.ac.za/handle/11660/9879 (accessed 23 March 2020

18. Du Plessis J. Stakeholders' viewpoints on work-integrated learning practices in radiography training in South Africa: Towards improvement of practice. Radiography 2019;25(1):16-23. https://doi.org/10.1016/j radi.2018.06.011

19. Berntsen K, Bjørk IT, Brynildsen G. Nursing students' clinical learning environment in Norwegian nursing homes: Lack of innovative teaching and learning strategies. Open J Nurs 2017;7(8):949-961. https://do org/10.4236/ojn.2017.78070

20. Trede F, Sutton K, Bernoth M. Conceptualisations and perceptions of the nurse preceptor's role: A scoping review. Nurs Educ Today 2016;36:268-274. https://doi.org/10.1016/j.nedt.2015.07.032

21. Tanner CA. Thinking like a nurse: A research-based model of clinical judgment in nursing. J Nurs Educ 2006;45(6):204-211. https://doi.org/10.3928/01484834-20060601-04

22. Al Moteri MO. Self-directed and lifelong learning: A framework for improving nursing students' learning skills in the clinical context. Int J Nurs Educ Scholar 2019;16(1):1-10. https://doi.org/10.1515/ijnes-2018-0079

23. Msiska G, Smith P. Fawcett T. The 'lifeworld' of Malawian undergraduate student nurses: The challenge of learning 3. Msiska G, Smith P, Fawcett T. The 'lifeworld' of Malawian undergraduate student nurses: The challenge of learn
in resource poor clinical settings. Int J Afr Nurs Sci 2014;1:35-42. https://doi.org/10.1016/jijans.2014.06.003

24. Gray A, Vawda Y. South African Health Review 2014/15. Durban: Health Systems Trust, 2015. https://doi org/10.1007/s13398-014-0173-7.2

25. Donovan P, Darcy DP. Learning transfer: The views of practitioners in Ireland. Int J Train Dev 2011;15(2):121-139. https://doi.org/10.1111/j.1468-2419.2011.00374.x

Accepted 24 June 2020 